\title{
ECTOPIC AUTOGRAFTS OF BLASTOCYSTS IN MICE MAINTAINED IN DELAYED IMPLANTATION
}

\author{
D. R. S. KIRBY \\ Department of Zoology, Parks Road, Oxford
}

(Received 2nd August 1967)

\begin{abstract}
Summary. During delayed implantation mouse blastocysts were transferred from the uterus to the animal's own kidney. Under the kidney capsule the blastocysts 'implanted' and developed normally, whilst those in the uterus remained in delay. The implications of these findings are discussed.
\end{abstract}

Mouse eggs taken from the genital tract and transplanted to extra-uterine sites 'implant' and develop independently of the endocrine state of the host. Their development is, however, greatly influenced by the state of differentiation of the egg when transplanted (Kirby, 1962, 1965). All previous accounts have dealt with eggs taken from the oviduct or uterus of a mouse during normal pregnancy ('normal' eggs). In these experiments eggs from mice in delayed implantation ('delayed' eggs) were used.

In sexually mature, randomly bred mice, eggs were prevented from implanting by removal of both ovaries. This operation was performed on sixteen mice on Day 1 of pregnancy (day of copulation plug = Day 0 ), and a further five mice on Day 2 of pregnancy. All mice were maintained on $2 \mathrm{mg}$ of progesterone in oil (s.c.) from the day of ovariectomy until autopsy. On Day 5 of pregnancy (i.e. 1 day beyond the normal time of implantation), none of the mice showed implantation sites, and an attempt was made to extract blastocysts from the left uterine horn whilst the mouse remained anaesthetized. This was done by gently flushing with physiological saline through a fistula whilst the horn was in situ or, in a few cases, by flushing after the horn had been removed from the body.

Blastocysts were found in eleven of the twenty-one mice and one (or in two cases two), blastocysts were taken up in a micropipette and transplanted to the animal's own kidney (autograft). Between 3 and 12 days later the mice were killed, and in all eleven animals a characteristic haemorrhagic nodule had developed on the kidney indicating that the extra-uterine blastocyst had implanted. The kidneys were fixed in Bouin's fluid and subsequent histological examination of the growths showed that in six of the eleven mice the blastocyst had given rise to an embryo of reasonably normal appearance (Plate 1). In 
the remaining five mice trophoblast only had developed. Flushings of the right uterine horn contained unimplanted blastocysts in seven of the eleven mice (Plate 1). The maximum period between ovariectomy and autopsy was 15 days; in this animal three blastocysts were recovered.

A further series of experiments showed that blastocysts were able to implant even after 6 days in the uterus of ovariectomized, progesterone-treated mice. Seven mice were ovariectomized on Day 1 of pregnancy and maintained on progesterone as before. On Day 8 , six of these mice received $0.04 \mu \mathrm{g}$ of oestradiol dipropionate subcutaneously. The seventh mouse had transplanted to its kidney an ovary from a genetically dissimilar mouse which was in oestrus. Autopsy 6 days after the oestrogen injection or the ovary transplant showed that implantation had occurred in five of the seven mice including the mouse carrying the transplanted ovary.

The following points emerge from these results.

(a) 'Delayed' blastocysts will implant and develop in an extra-uterine site. Indeed, both the incidence of implantation and the development of an embryo appears to be superior to that of 'normal' blastocysts transferred to a similar site (Kirby, 1962). This may be due to the 'delayed' eggs being subjected for a prolonged period of time to the 'uterine factor' postulated in an earlier publication (Kirby, 1962, 1965). This uterine factor appears to induce in mouse eggs the capacity to give rise to an embryo, rather than trophoblast and extra embryonic membranes alone.

(b) Blastocysts in ovariectomized, progesterone-maintained mice can be induced to implant by the administration of $0.04 \mu \mathrm{g}$ of oestradiol dipropionate. This quantity compares well with the amount $(0.05 \mu \mathrm{g})$ used by Yoshinaga \& Adams (1966) to induce implantation under similar conditions, and with the quantity $(0.01$ to $0.25 \mu \mathrm{g})$ found by Finn (1966) to give a maximal decidual response to an intra-luminal injection of oil in ovariectomized mice maintained on progesterone. One must assume that the failure by Dickson \& Araujo (1966) to induce implantation with oestrogen in progesterone-maintained ovariectomized mice was due to the excessive dose of oestradiol used $(0.5$ to $5 \cdot 0 \mu \mathrm{g})$.

(c) The extra-uterine placentae did not secrete sufficient oestrogen to induce those eggs in the uterus to implant. This finding supports that of Harkness, McLaren \& Roy (1964) who, by chemical assay, were unable to detect oestrogen in the mouse placenta.

(d) Following ovariectomy on Day 1 of pregnancy, none of the twenty-one mice showed implantation when inspected 5 days later. This is difficult to reconcile with the recent findings of Yoshinaga \& Adams (1966) who found that a third of the mice ovariectomized at a similar time implanted normally, whereas if surgery was postponed to the following day none implanted. They suggest that hormonal requirements for implantation following ovariectomy vary according to the time of ovariectomy. In view of the present results, and the situation in the rat in which total ovariectomy at this time completely inhibits implantation (Psychoyos \& Alloiteau, 1962; Nutting \& Meyer, 1963), one must suspect that such implantation in the mouse is the result of incomplete 


\section{PLATE I}

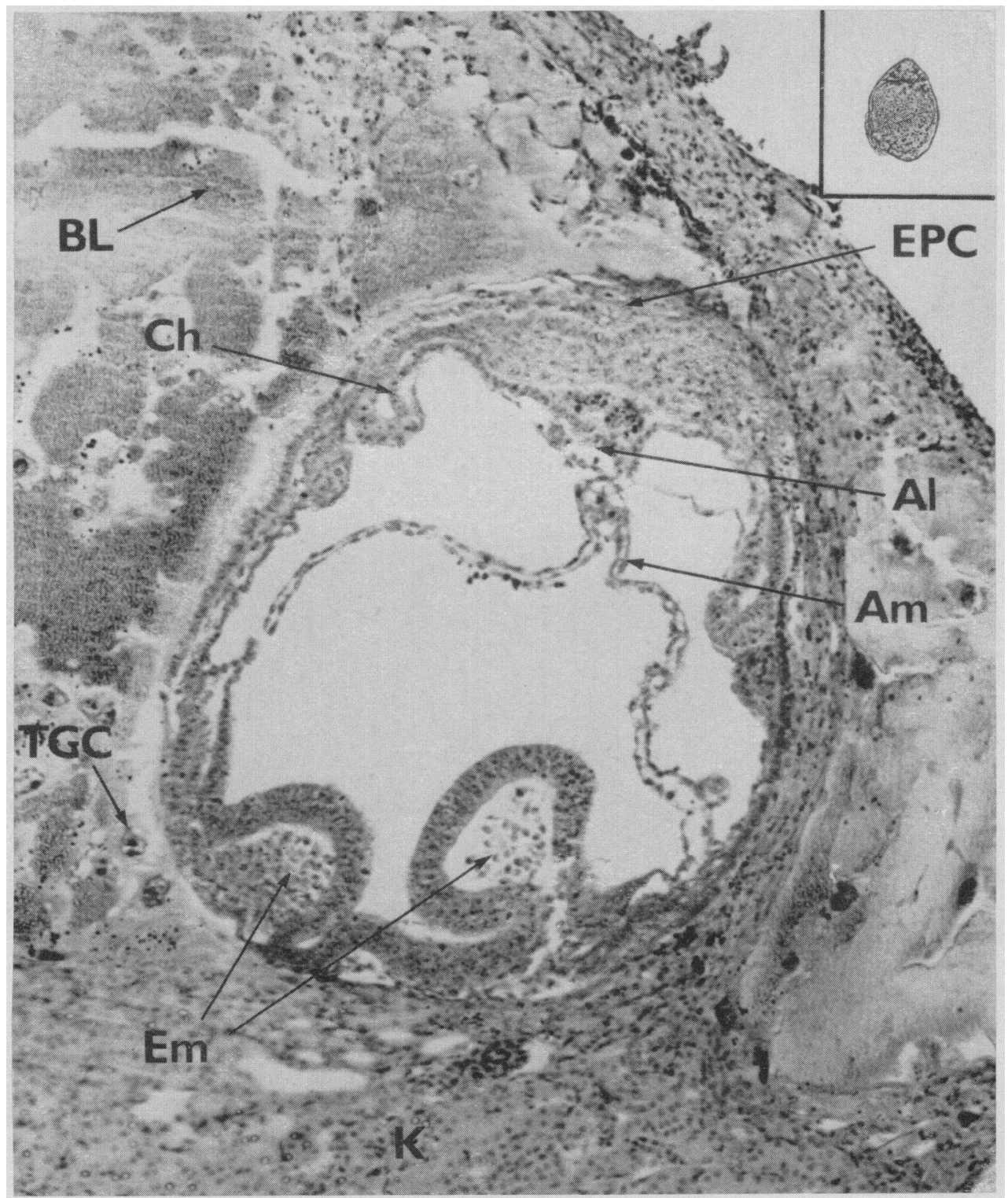

Embryo developing on the kidncy, and blastocyst from the uterus (inset). Both removed from the same mouse 9 days post coitum. Blastocyst was transferred from the uterus to the kidney 4 days before autopsy. $(\times 100)$.

$\mathrm{BL}=$ Blood lacunae; $\mathrm{EPC}=$ ectoplacental cone; $\mathrm{Ch}=$ chorion $; \mathrm{Al}=$ allantois $\mathrm{Am}=$ amnion $; \mathrm{TGC}=$ trophoblast giant cell; $\mathrm{Em}=$ embryo showing infolding of ectoderm; $\mathrm{K}=$ kidney.

(Facing p. 516) 
ovariectomy. Radical surgery is not possible when removing the ovary shortly after ovulation otherwise the eggs, which are in the upper portion of the oviduct, will be dislodged. As the eggs progress towards the uterus more complete surgery is feasible.

\section{REFERENCES}

Dickson, A. D. \& Araujo, H. B. (1966) Dissociation of trophoblastic giant cell transformation from implantation of mouse blastocysts. F. Endocr. 36, 325.

FinN, C. A. (1966) Endocrine control of endometrial sensitivity during the induction of a decidual cell reaction in the mouse. 7. Endocr. 36, 239.

Harkness, R. A., McLaren, A. \& Roy, E. S. (1964) Oestrogens in mouse placentae. J. Reprod. Fert. 8,411 .

KIRBY, D. R. S. (1962) The effect of the uterine environment on the development of mouse eggs. 7. Embryol. exp. Morph. 10, 496.

KIRBY, D. R. S. (1965) The role of the uterus in the early stages of mouse development. In: Ciba Foundation Symposium: Preimplantation Stages of Pregnancy. Eds. G. E. W. Wolstenholme and M. O'Connor. Churchill, London.

NutTing, E. F. \& MEYER, R. K. (1963) Implantation delay, nidation and embryonal survival in rats treated with ovarian hormones. In: Delayed Implantation. Ed. A. C. Enders. University of Chicago Press.

Psychoyos, A. \& Allorteau, J. J. (1962) Castration précoce et nidation de l'œuf chez la ratte. C. r. Séanc. Soc. Biol. 156, 46.

Yoshinaga, K. \& Adams, C. E. (1966) Delayed implantation in the spayed, progesterone treated adult mouse. 7. Reprod. Fert. 12, 593. 